\title{
Probabilistic Analysis of Shallow Foundation Settlement considering Soil Parameters Uncertainty Effects
}

\author{
Mahmoud Nazarzadeh, Soheil Sarbishe-ee \\ Department of Civil Engineering, Geotechnical, E-Campus Branch, Islamic Azad University E Campus, Tehran, Iran \\ Email: nazarzadeh.m@yahoo.com
}

How to cite this paper: Nazarzadeh, M. and Sarbishe-ee, S. (2017) Probabilistic Analysis of Shallow Foundation Settlement considering Soil Parameters Uncertainty Effects. Open Journal of Geology, 7, 731743.

https://doi.org/10.4236/ojg.2017.75049

Received: March 3, 2017

Accepted: May 24, 2017

Published: May 27, 2017

Copyright ( 92017 by authors and Scientific Research Publishing Inc. This work is licensed under the Creative Commons Attribution International License (CC BY 4.0).

http://creativecommons.org/licenses/by/4.0/

(c) (i) Open Access

\begin{abstract}
One of the most important challenges in the design of the foundation of the Earth layer below the surface is the Summit Foundation, which can be a very large impact on the sustainability and the structure of the desired user. Based on this analysis and design criteria of two successive ruptures (load bearing) and settlement, due to the nature of non-homogeneous soil and its parameters uncertainty, relying on one number as the amount of foundation settlement doesn't seem logical. This is while in the methods of the probability distribution function by taking the probability for each of the input parameters, or the characteristics of each parameter, the parameter values are likely to have the chance of occurrence. In this research, effort is made using the method of probabilistic Monte Carlo simulation, the effect of the uncertainty of parameters influencing the mechanical behavior following the successive layers of earth and examined. In the event that non-deterministic model input variables for describing, not non-deterministic model output as well. So the output of each method to analysis of the concept of the probability distribution function for the input variables is a function of the probability distribution for the target function. In this study, the reliability of the settlement for the three modes of settlement center, corner of rigid foundation is fitted with two types of normal probability distribution and the log-normal distributions. For this purpose, the parameters of the effect of the transition on the analysis of soil modulus of elasticity of foundation, such as settlement and the coefficient of Poisson ratio distribution in probability using probabilistic log-normal and normal have been considered. Analysis indicated that the settlement in the center of the wake is flexible critical than the other two and has a higher probability of occurrence of the settlement in this part of the foundation. In the case of the normal distribution and the normal distribution graph of the log was used, the probability density function of the normal distribution is related to the log has a greater dispersion.
\end{abstract}




\section{Keywords}

Settlement Foundation, Reliability, Uncertainty, The Log-Normal

Distribution, Normal Distribution

\section{Introduction}

One of the major challenges in designing shallow foundations is subsidence of layers of earth under the foundation that can have a huge impact on the stability and use of the structure in question. Accordingly, in the analysis of foundations, failure criteria (bearing capacity) and subsidence are used [1]. Monte Carlo simulation method for the determination of model uncertainty, a little bit for each of the input random variables is a function of the probability distribution is considered.

In these analyses, in the first case, the amount of force that the foundation can transfer to the layers of subsoil, or the maximum bearing capacity of the subsoil should be determined, and in the second case, maximum subsidence happened in the subsoil should be determined using the effective parameters [2]. In the designing foundation, usually the subsidence determined is more critical than the force that foundation can transfer to the subsoil. As a result, usually in designing foundation, subsidence will be decisive [2]. This kind of simulation is uncertainty in different aspects of the issue clearly show slightly. Monte Carlo methods to quantify uncertainties in model, a probability distribution function for each input random variables is considered. If uncertain input variables as described in the model, the model outputs are necessarily uncertain. The output of each method for analyzing the concept of probability distribution function for input variables using a probability distribution function for the objective function [3].

\section{Problem Statement}

The load of a building is borne by the foundation and in some cases is transferred to the soil and borne by soil layers. Given that in case of failure of this part of the structure, there is less possibility to repair, rebuild, etc., designing of this part of the structure must be done with great precision [4].

Normally, by carrying out a few tests, the mechanical parameters affecting soil behavior are determined at some points and by averaging the analyses are made based on these parameters [3]. The other method is using probabilistic methods and combining them with geotechnical engineering analysis methods. In these methods, the effect of all possible parameters will be included in the calculations, so analyses precision will increase and share of all the errors will be considered in these analyses [5].

In this research, effort will be made to use probabilistic Monte Carlo simulation method to assess the effect of uncertainties parameter affecting the mechanical behavior of successive layers of earth underneath. This is a kind of si- 
mulation where uncertainty in various aspects is shown clearly and quantitatively [6]. In Monte Carlo method, a probability distribution function is considered for each input random variable to quantify uncertainties in the model. If the input variables are described as uncertain, model outputs are necessarily uncertain [7]. Thus, the output of each method that uses the concept of probability distribution function for analyzing for the input parameters will be a probability distribution function for the objective function [8].

\section{Review of Literature}

Studies by Griffith et al.

In this paper, a study is conducted to investigate the probabilistic bearing capacity of strip foundations on the earth without weight by using the theory of random field. Modeling is done in two forms: (Figure 1), in a case, strip foundation is used and in another case, two strip foundations are considered in parallel [9].

Stochastic finite element method has been used in this article. This method is a combination of finite element method, random field theory, and probabilistic Monte Carlo simulation method. Soil shear strength is considered in probabilistic form by using lognormal probability distribution [9].

The study by Fenton et al.

In this article, the reliability of subsidence under foundation has been analyzed in three-dimension mode. For this purpose, the modulus of elasticity of the soil is considered using the probability distribution of normal log [9]. The subsidence under single and double square foundations has been determined using

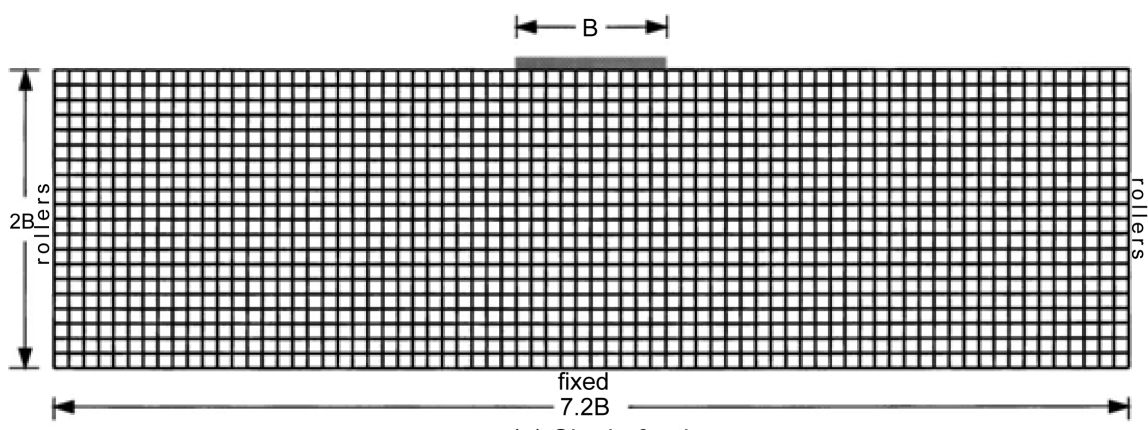

(a) Single footing

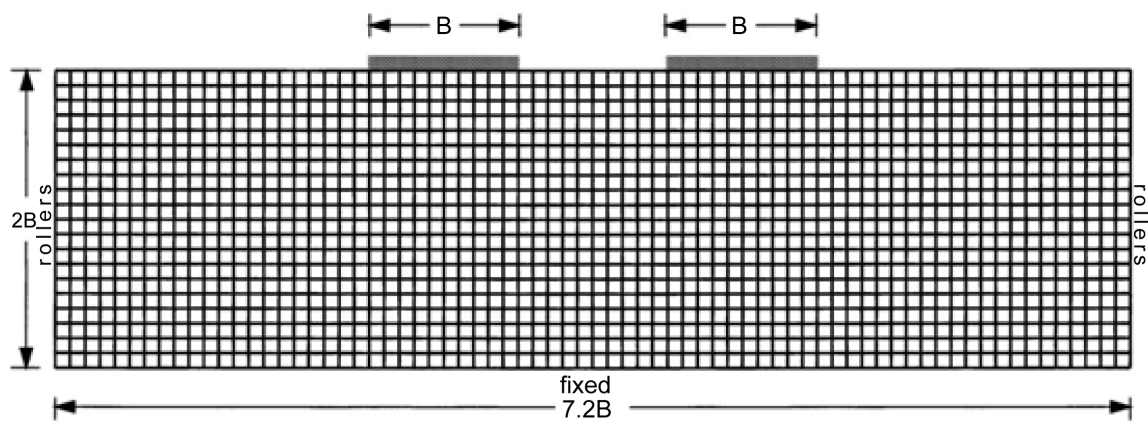

(b) Two footings

Figure 1. Models studied [9]. 
three-dimensional finite element method. The model used in the analysis is presented in the (Figure 2) below [10].

Using limited random running method the desired results are determined and compared with the results provided by the Monte Carlo method [1]. Determined probabilistic distribution for the following subsidence under the foundation has been set as normal distribution and lognormal. As you can see in the (Figure 3) below, it is properly presented.

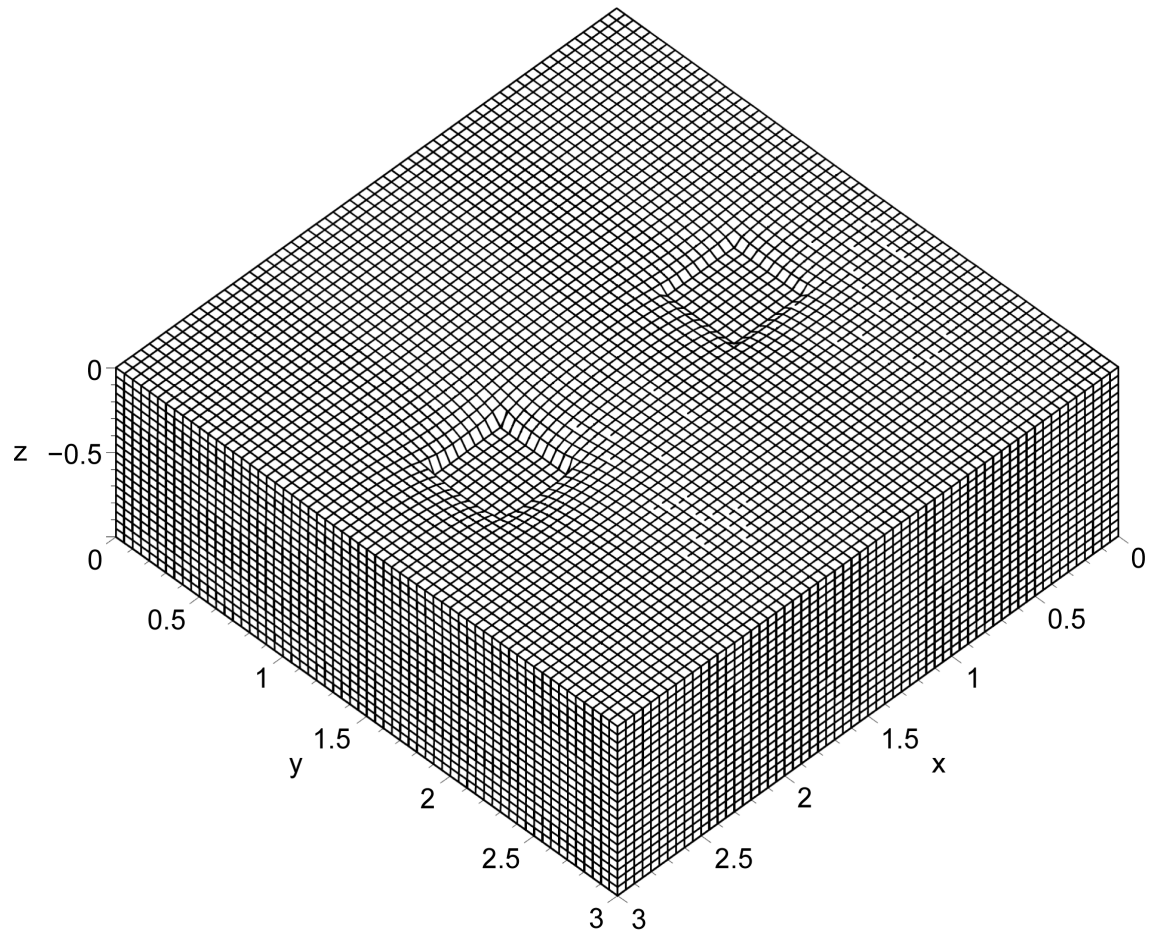

Figure 2. Modeled three-dimensional model [1].

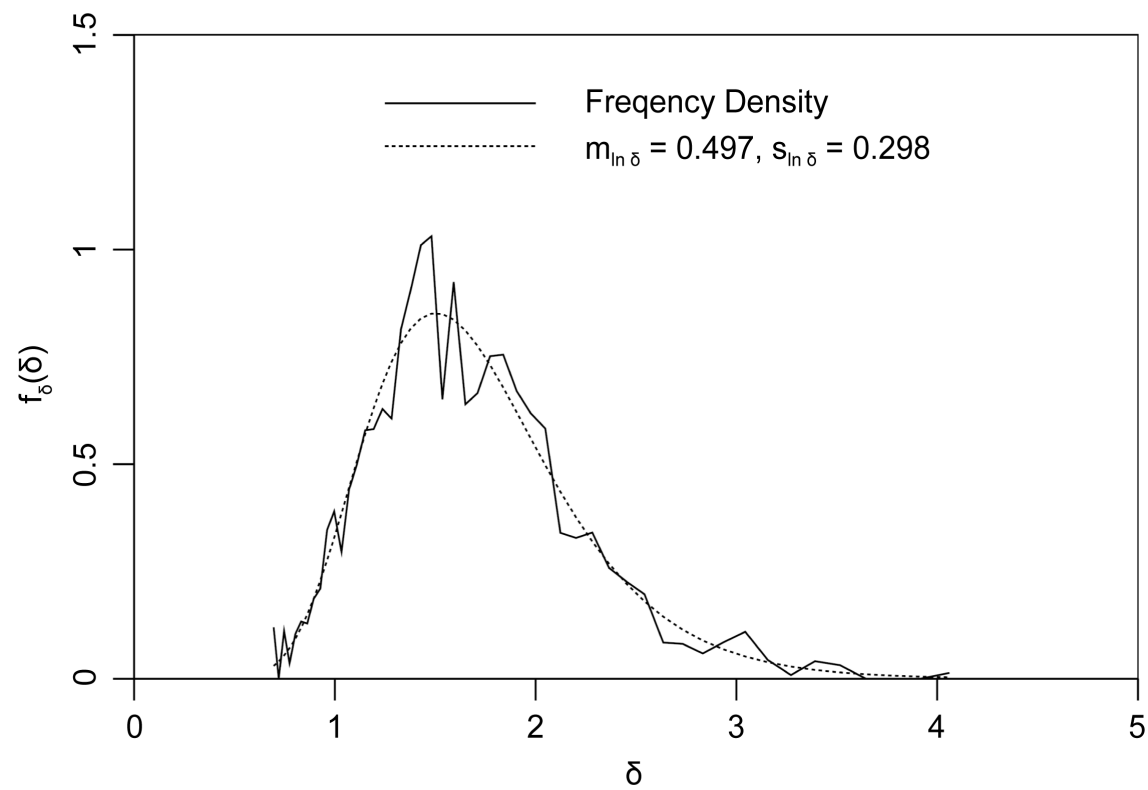

Figure 3. Determined probabilistic distribution for under foundation subsidence [1]. 
The study by Wang et al.

In this paper, Monte Carlo and LS-SVM methods have been used for assessing the reliability of subsidence of the area below shallow foundations. One of the most important parts of LS-SVM method is selecting input data. For this purpose, categorizing of the available was used in nine levels, and output data is used by using the fast Lagrangi an analysis method in continuous environment (FLAC). The algorithm determined for selecting input data at nine different levels is presented in the (Figure 4) [11].

After determining the input data, selected data is used to determine the probability distribution, then output data is determined using LS-SVM method, and finally using Monte Carlo simulation (MCs) and codes written in MATLAB, the reliability of the subject is determined. The method of calculation is provided based on a flowchart of the (Figure 5).

Results showed that combining LS-SVM and MCs methods has good capability of reliability in determining subsidence under the foundation. The designated subsidence and subsidence predicted based on probabilistic methods are presented in the (Figure 6). As is seen in the figure, designated answers have enough harmony with their values [12].

\section{Hypotheses and Research Questions}

The average value of the specified subsidence in the use of probabilistic methods has the probability of occurrence of 50 percent.

What effects does uncertainty of strength and influential parameters of the soil have on the creation of subsidence in the soil beneath shallow foundations?

\section{Research Methodology}

Having the exact distribution of stress in the depth is the necessary condition for the exact estimation of the subsidence but not sufficient. To investigate the effect of uncertainty of soil parameters on foundation subsidence, computer programs required must be written manually. To this end, first by writing computer programs using MATLAB software, we probabilistically investigate the foundation

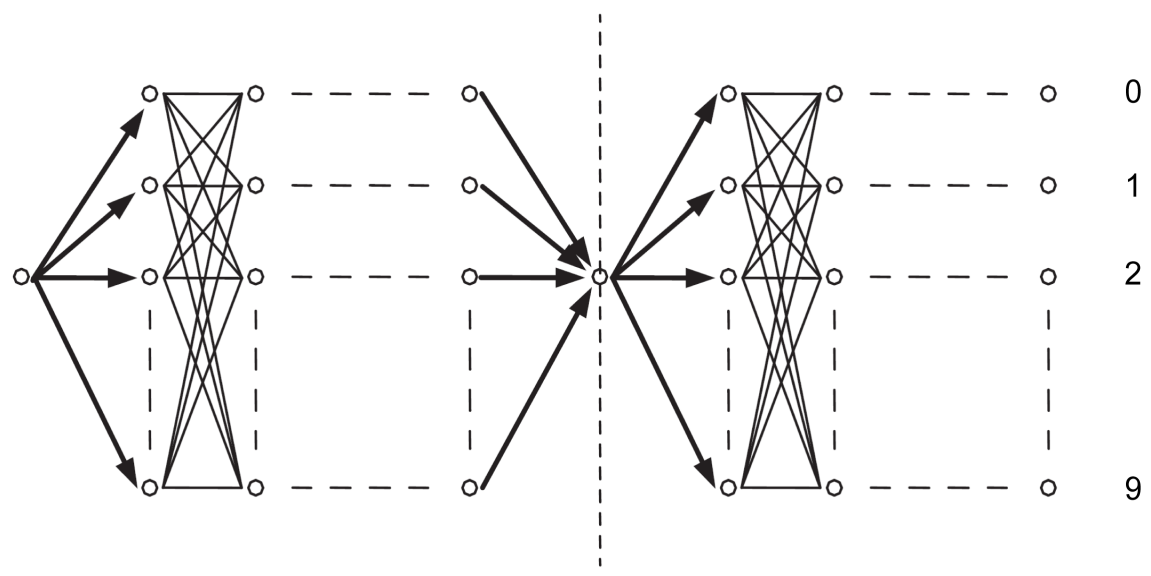

Figure 4. Algorithm determined for selecting input data set at nine different levels [12]. 


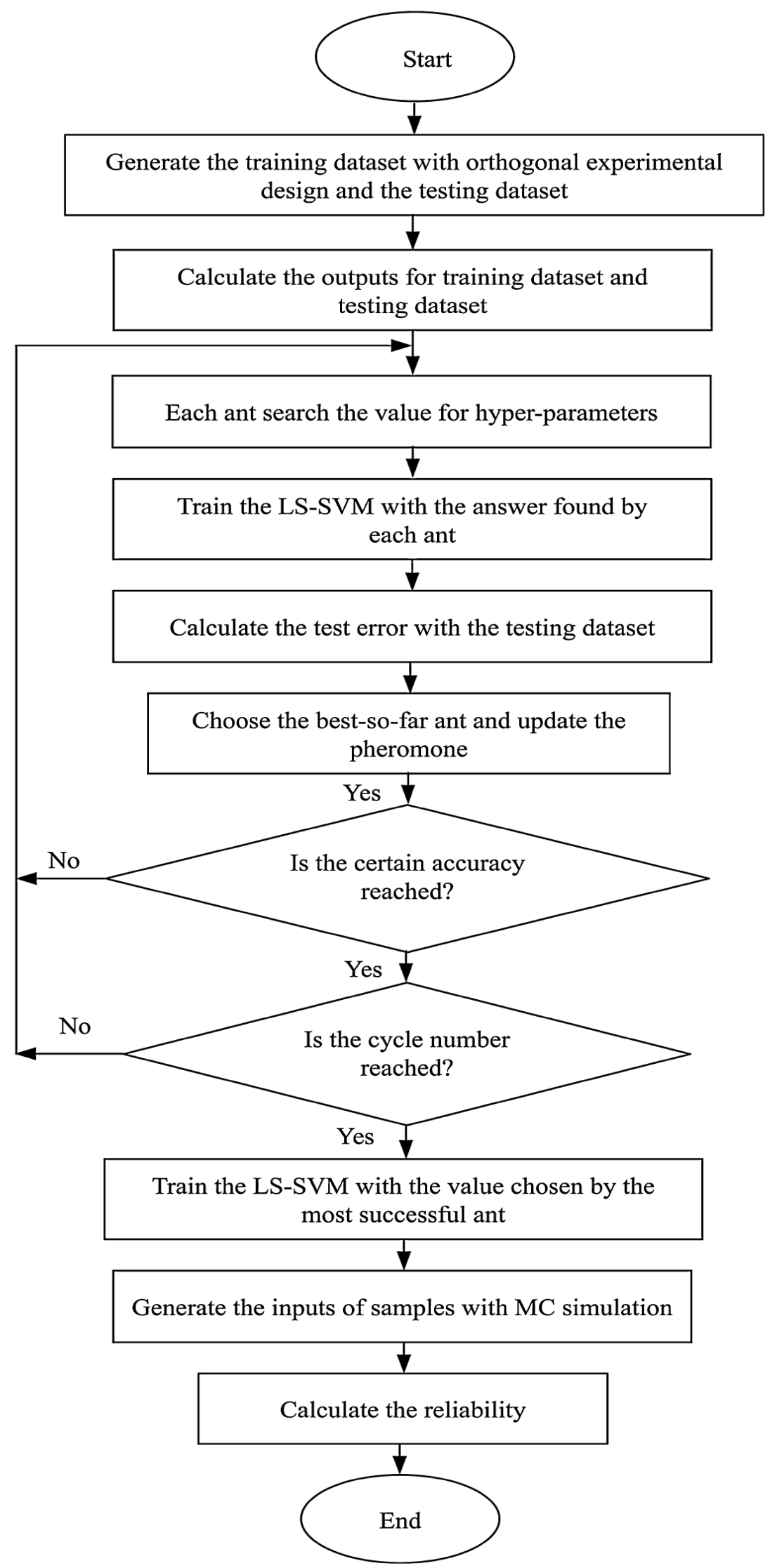

Figure 5. Calculation method based on the flowchart [12]. 


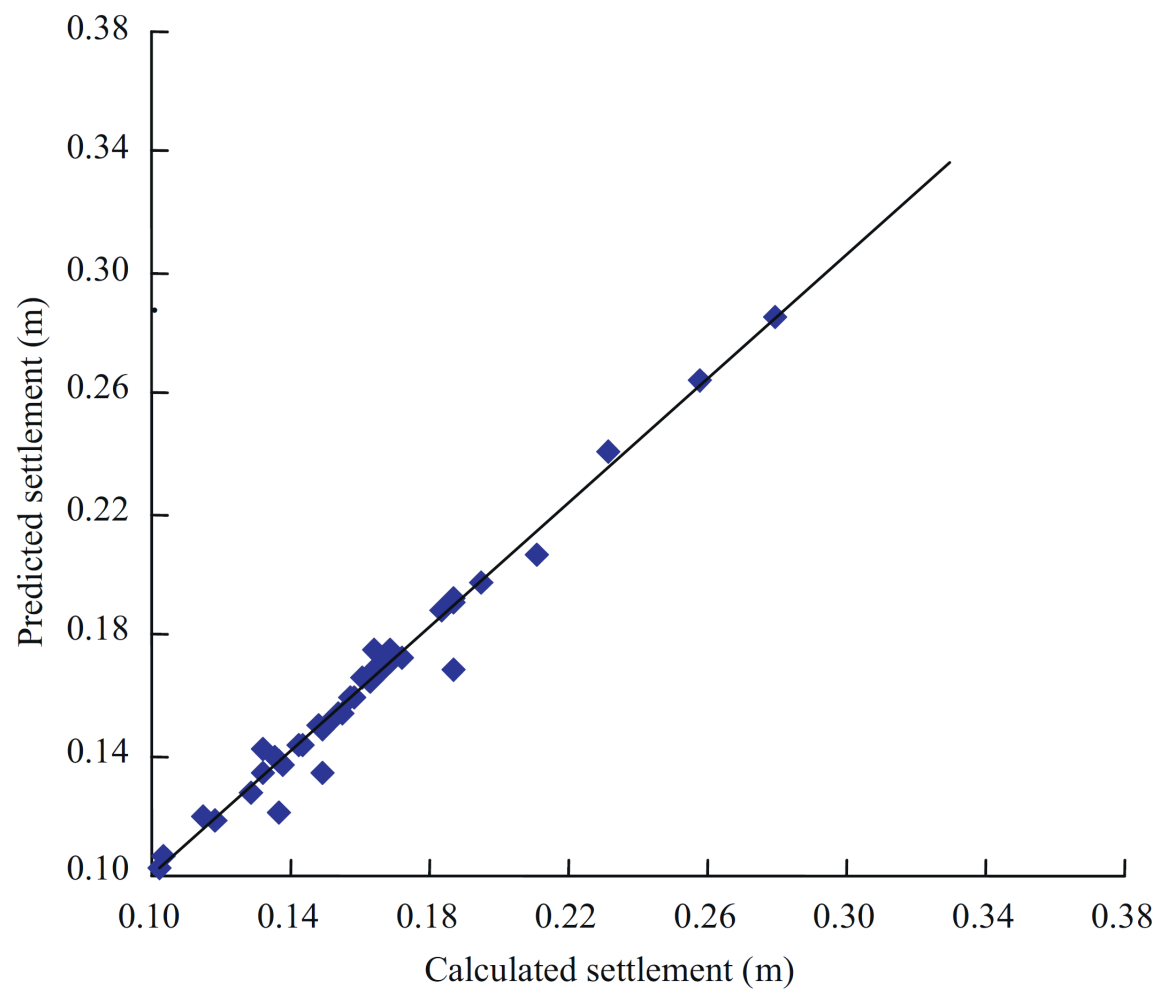

Figure 6. The performance of LS-SVM method to determine the subsidence under foundation [12].

rupture force, and then using other apps (using MATLAB) determine the probability distribution of the subsidence under foundation. It should be noted that in this study for separate analysis, finite element software GeoStudio would be used [13].

\section{Foundation Subsidence}

Subsidence of structures happens by shape change, shifting land, change in the volume of soil or substructure under stress from loading and unloading. Deformation under constant effective stress is called creep, while deformation under increasing tension is called displacement or compression. The above changes in shape are the results of the elastic and plastic deformations of seeds, soil mass change due to exit of water and air from the pores and shear displacement of soil particles [13].

For fine-grained soils such as silt and saturated or close to saturation clay, permeability is low. The subsidence in them due to slow fading of extra pressure of pore water related to loading and subsequent reduction of porosity requires a relatively long time, so prediction of the subsidence and the time required in the calculations are of great importance [13].

\section{Factors Affecting the Subsidence}

The following factors cause soil subsidence, which include:

1) Soil loading and compaction due to compressive stress that is relatively 
high and as a set of elastic and plastic deformation.

2) Loading and displacement of soil particles by applying shear forces that for instance, in loose sand reduce the volume and in compacted sand increase volume.

3) Initial strengthening or consolidation of the soil due to applying load and the subsequent increase in pore water pressure in saturated soil structure over the water in the pores of the soil as a result of the pressure difference, drainage and extraction, consequent displaced soil particles to partially fill the void left by the withdrawal of water. For fine-grained soils with low permeability such as clay, consolidation phenomenon is slow and may take years and even until the end of the useful life of structures.

4) Creep or secondary consolidation: after the completion of the initial consolidation process, volume changes in soil under constant effective stress may continue that is called secondary consolidation or creep. Explanation of this phenomenon is not entirely clear but its occurrence can be attributed to the exit of water from microscopic pores or slimy deformation.

5) Failure to comply with technical considerations in the construction of superstructure and substructure will be associated with deformations of materials used in the short and long term. In case of the construction of the foundation on embankment and especially the fine-grained and non-dense type, there is a high probability of subsidence.

6) Incidents in the soil during excavation including swelling after drilling, softening of some soil and rocks due to environmental factors, the occurrence of water moving at high speed in the sand and silt, erosion and sensitivity in clay and silt.

\section{Modeling Foundation Subsidence with Geo-Studio Software}

For validation and examining flexible foundation behavior using Finite Element Method (FEM), we attempted to model subsidence under foundation using Geo-Studio FEM software. For this purpose, we considered a square foundation in 3 and 7 meters in size.

In general, GeoStudio software is composed of 8 sub-software, each of which performs the specialized analysis of one of the areas of geotechnical engineering. In this study, SEEP/W, QUACK/W, SLOPE/W and SIGMA/W sub-software is used. QUACK/W is used for analysis before and after the earthquake. SLOPE/W does stability analysis of dusty slopes. SIGMA/W is used to review stress changes and transformations happened.

The first step for analysis is modeling in GeoStudio, and to do so, based on the size and shape, modeling should be done. One of the most important parts is defining influential parameters in the model, which were correctly set and entered based on these parameters. For the intended model, we set and entered the parameters from menu of definition of parameters material.

Then using the command Draw Regions, we defined the areas where the soil 
type should be imported. Having defined the areas, we considered the materials defined for each area. Accordingly, the following areas (Figure 7) were defined.

One of the most important steps in modeling in FEM software is proper definition of boundary conditions of the desired structure. Given that in the present model, analyses are of several types and with different boundary conditions, thus the modeling will be more and more complex. For example, boundary conditions defined are presented in the (Figure 8).

In the Figure 8, boundary conditions are shown for the intended model. In this model, movement in $\mathrm{X}$ and $\mathrm{Y}$ directions for the left and right sides of the model is restricted, and for the area below the intended area, movement is limited. The intended foundation has entered the model to the amount of $300 \mathrm{kPa}$ as blue and as one of the boundary condition of the model. After conducting stress-strain analyses and determining displacements and subsidence occurred under the foundations, designated contours can be shown as the (Figure 9) below. In the following figure, movements occurred in the vertical direction under foundation are presented.

As can be seen in the figure above, by applying loading on the soil due to foundation, some displacements occur under foundation. The amount and magnitude of these displacements under the foundation are shown using red.

As can be seen in the (Figure 10), the size and density of the vectors of foundation is more than other parts. Vertical displacement occurred in the foundation is presented in the graph of (Figure 11).

As can be seen in Figure 11, the maximum displacement is in the center as -0.105 meters. By getting away from the center of the foundation and moving in

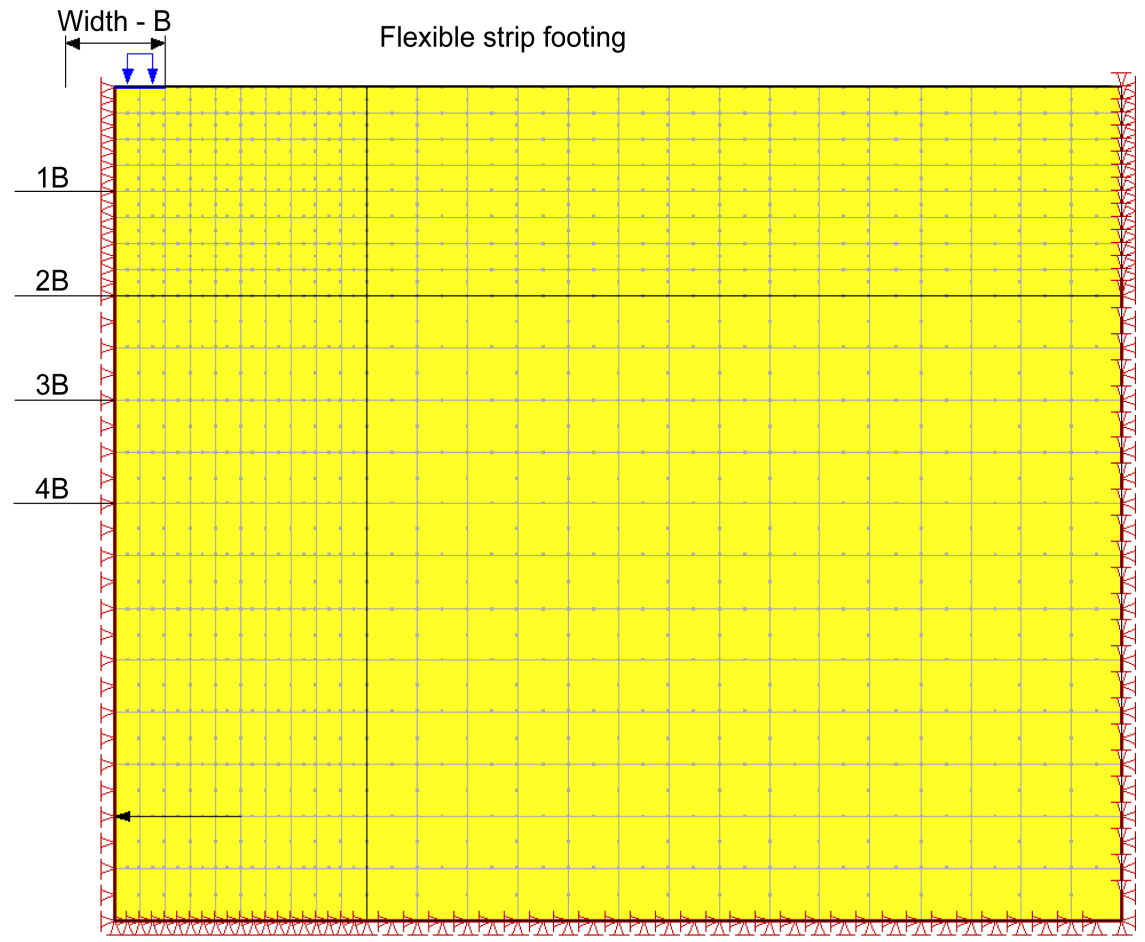

Figure 7. Modeled section in Geo-Studio. 


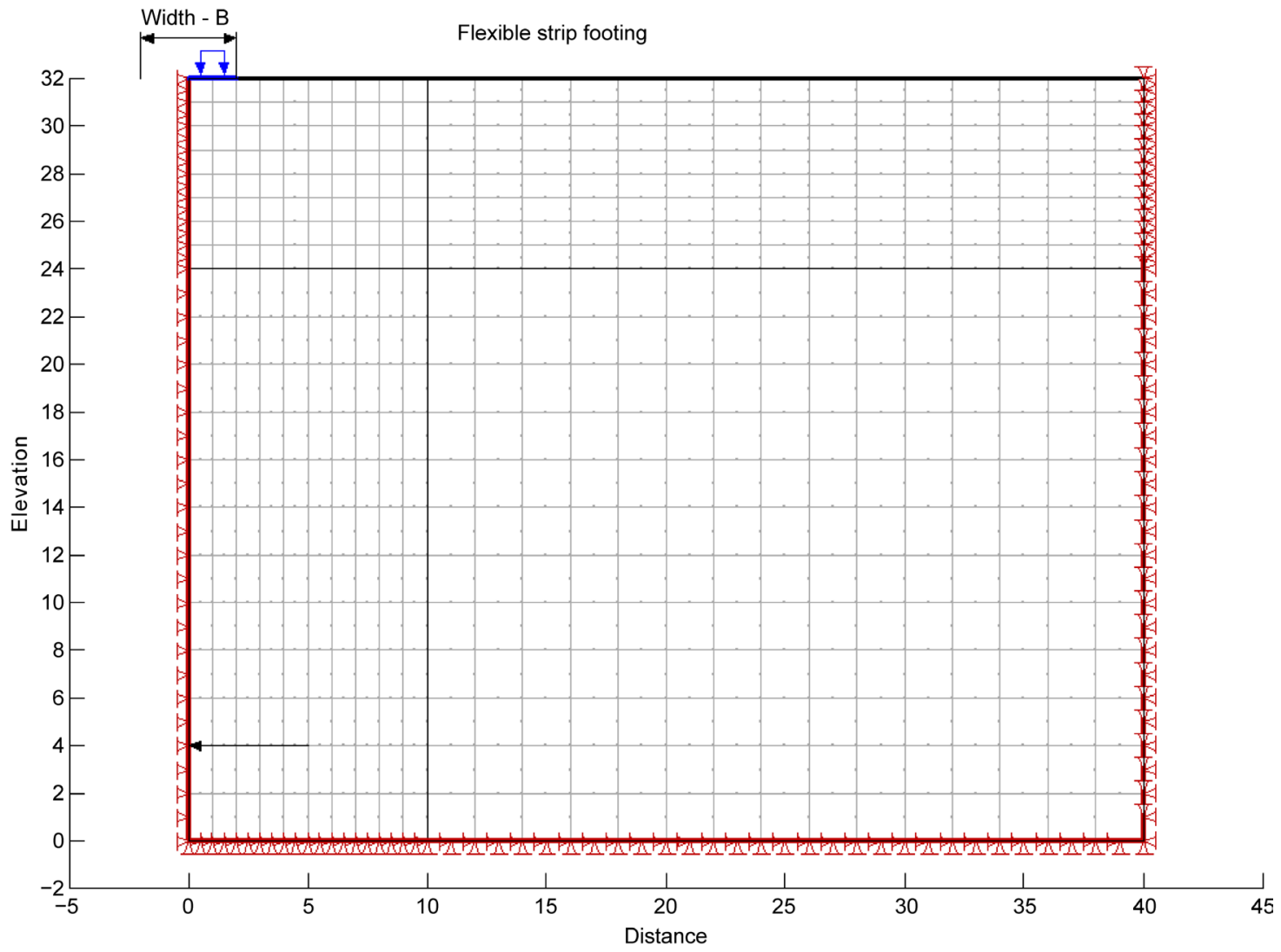

Figure 8. Boundary conditions for FEM analyses of subsidence in Geo-Studio.

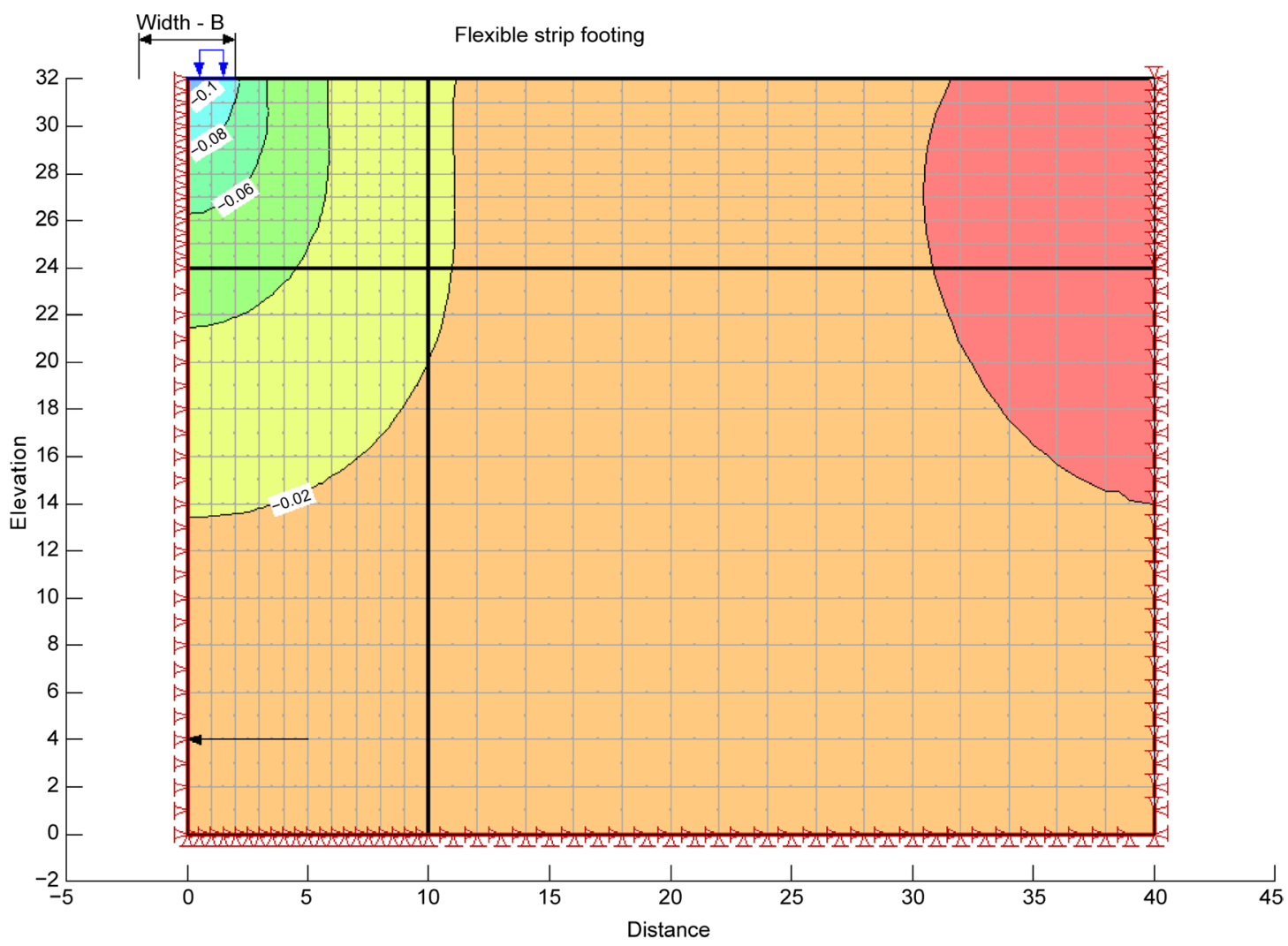

Figure 9. Deformation under foundation in the vertical direction. 


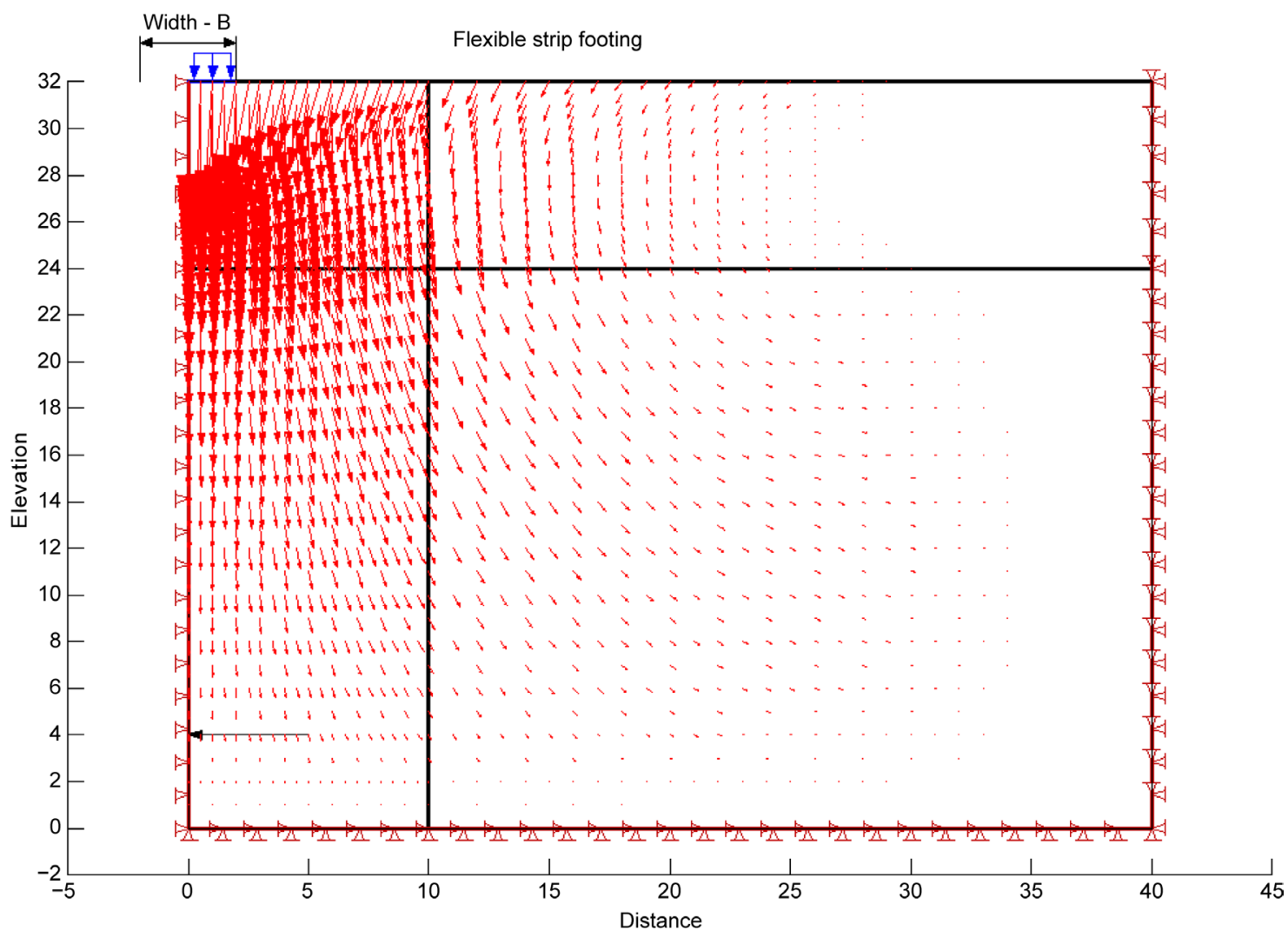

Figure 10. Displacements occurred in the foundation.

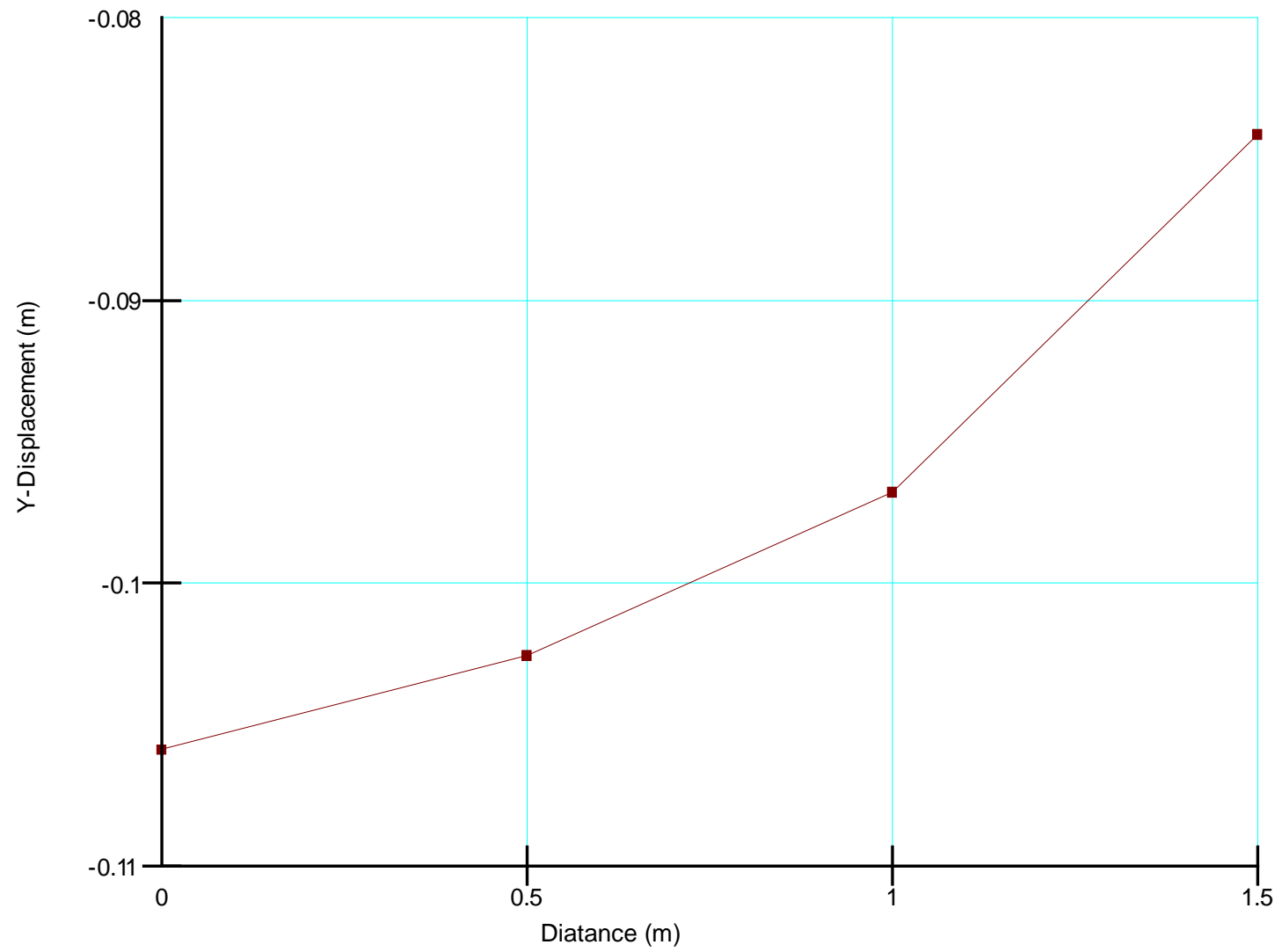

Figure 11. Vertical displacement under the foundation. 
the direction away from it, it can be observed that this value reduces and reaches -0.085 . Accordingly, it can be noted that by distancing from the center, the subsidence of under the foundation reduces.

\section{Conclusions}

The results of this study are presented in the following section:

1) Based on the analyses, using FEM software Geo-Studio, the largest displacement is in the center of the strip foundation as -0.105 meters, and by getting away from the center of the foundation and moving in the direction away from it, it can be observed that this value reduces and reaches -0.085 . Value is reduced and the amount of -0.085 .

2) Soil behavior under strip and circular foundations is almost the same behavior.

3) By reviewing CDF chart and comparing with CDF graph, it was found that in PDF graph, the probability of subsidence is average (0.0879) equal to $50 \%$, and it is proven in the analyses undertaken [14].

4) By comparing CDF graph related to subsidence of the center and corners of the foundation and rigid foundation, it can be seen that their order of placement is similar to the order of the corresponding PDF graphs. Based on these figures, the probability of subsidence of 0.075 for the center of the foundation is $20 \%$ for rigid foundation is $30 \%$, and $100 \%$ for corner of flexible foundation. Accordingly, the probabilistic subsidence behavior of flexible foundation at the center can be more critical than the other states, and dispersion determined for it is more than other states [14].

5) In case of using distribution of lognormal, the average values determined for the probabilistic distribution of subsidence have great concordance with average values of normal probability distribution. According to PDF charts drawn, it can be seen that the dispersion of the probabilistic distribution of lognormal is more than the normal probability distribution.

6) The order of arrangement of PDF and CDF charts, where the lognormal distributions is used is as in the case in which the normal distribution is used. In this case, we can see that the subsidence values determined for the center and corners of flexible foundation are, respectively, the highest and lowest values had been determined, and PDF and CDF charts related to the subsidence in rigid foundation were in the middle of these charts.

7) By increasing the diameter of circular foundations, the likelihood of subsidence of rigid foundation increases, and this increase has linear relationship with increase in the diameter of the foundation. Thus, in a circular foundation with a diameter of $1.5 \mathrm{~m}$, the probability has been $24 \%$ and in circular foundation with a diameter of 4 meters, the probability has reached $31 \%$.

8) The probability of subsidence of the center of flexible foundation in circular foundations increases with increase in diameter, so that in a foundation with a diameter of 1.5 meters, the probability is $85 \%$, and in circular foundations with a diameter of 4 meters, it reaches $98 \%$. 


\section{References}

[1] Shallow Foundations, Kimmerling, R.E. (2002) Geotechnical Engineering Circular No. 6, FHWA-SA-02-054, September 2002.

[2] Vesic, A.S. (1973) Analysis of Ultimate Loads of Shallow Foundations. Journal of the Soil Mechanics and Foundations Division, 99, 45-73.

[3] Das, B.M. and Larbi-Cherif, S. (1983) Bearing Capacity of Two Closely Spaced Shallow Foundations on Sand. Soils and Foundations, 23, 1-7. https://doi.org/10.3208/sandf1972.23.1

[4] Terzaghi, K. and Peck, R.B. (1967) Soils Mechanics in Engineering Practice. John Wiley \& Sons, New York.

[5] Brzakała, W. and Pula, W. (1996) A Probabilistic Analysis of Foundation Settlements. Computers and Geotechnics, 18, 291-309.

[6] Griffiths D.V., Fenton, G.A. and Manoharan, N. (2006) Undrained Bearing Capacity of Two-Strip Footings on Spatially Random Soil. International Journal of Geomechanics, 6.

[7] Fenton, G.A. and Griffiths, D.V. (2002) Probabilistic Foundation Settlement on a Spatially Random Soil. ASCE Journal of Geotechnical and Geoenvironmental Engineering, 128, 381-390. https://doi.org/10.1061/(ASCE)1090-0241(2002)128:5(381)

[8] Fenton, G.A. and Griffiths, D.V. (2005) Three-Dimensional Probabilistic Foundation Settlement. ASCE Journal of Geotechnical and Geoenvironmental Engineering, 131, 232-239. https://doi.org/10.1061/(ASCE)1090-0241(2005)131:2(232)

[9] Wang, Y., Zhao, X. and Wang, B. (2013) LS-SVM and Monte Carlo Methods Based Reliability Analysis for Settlement of Soft Clayey Foundation. Journal of Rock Mechanics and Geotechnical Engineering, 5, 312-317.

[10] Dubost, J., Denis, A., Marache, A. and Breysse, D. (2011) Effect of Uncertainties in Soil Data on Settlement of Soft Columnar Inclusions. Engineering Geology, 121, 123-134.

[11] Aysen, A. (2002) Soil Mechanics, Basic Concepts and Engineering Applications. Balkema Publishers.

[12] Kempfert, H.G. and Gebreselassie, B. (2006) Excavations and Foundations in Soft Soils. Springer, Berlin.

[13] Fang, H.Y. (2001) Foundation Engineering Handbook. 2nd Edition, CBS, 537-555.

[14] Tomlinson, M.J. (2001) Foundation Design and Construction. 7nd Edition, CEng, FICE, FIStructE, 278-341. 
Submit or recommend next manuscript to SCIRP and we will provide best service for you:

Accepting pre-submission inquiries through Email, Facebook, LinkedIn, Twitter, etc. A wide selection of journals (inclusive of 9 subjects, more than 200 journals)

Providing 24-hour high-quality service

User-friendly online submission system

Fair and swift peer-review system

Efficient typesetting and proofreading procedure

Display of the result of downloads and visits, as well as the number of cited articles Maximum dissemination of your research work

Submit your manuscript at: http://papersubmission.scirp.org/

Or contact ojg@scirp.org 